\title{
Control of pigeons' keypecking by the left-right arrangement of stimuli
}

\author{
DONALD M. WILKIE, MARCIA L. SPETCH, and LESLIE G. LEADER \\ University of British Columbia, Vancouver, Canada V6T IW5
}

\begin{abstract}
Control of pigeons' keypecking by conditionalities in the spatial arrangement of two element stimuli (designated A and B) was investigated. In Experiment 1, reinforcement for keypecking was made conditional upon the left-right location of $\mathrm{A}$ and $\mathrm{B}$ : Reinforcement was available when $A$ was on the left and $B$ was on the right $(A B)$, but not on BA, AA, or BB trials. The pigeons successfully discriminated the rewarded AB configuration, but only after a stage in which a particular element in a particular location (e.g., A on left) primarily controlled pecking. Experiments 2 and 3 systematically replicated these findings and included controls to discount discrimination of the $\mathrm{AB}$ compound on the basis of the temporal order (e.g., A followed by B) rather than the spatial configuration of the elements. During a generalization test in Experiment 4, the elements were presented singly either in the left (AX, BX) or right (XA, XB) positions. As would be expected had the animals learned "A on the left, $\mathrm{B}$ on the right is rewarded," responding on $\mathrm{AX}$ trials exceeded that on XA trials, and responding on XB trials exceeded that on BX trials.
\end{abstract}

A stimulus present at the time a response produces reinforcement often controls responding: Responding is less likely to occur when the stimulus is absent. This is especially true when, during discrimination training, this stimulus alternates with another during which reinforcement is unavailable. It is possible to arrange that two stimuli (referred to here as elements) be present at the time of reinforcement. This compound will control responding if the compound is alternated with nonrewarded individual elements (cf. Kehoe \& Gormezano, 1980).

Such a compound is defined by the simple presence of two elements. It is possible to construct more elaborate compounds. Besides requiring that both elements (say, " $A$ " and 'B") be present before reinforcement is available, one can introduce additional conditionalities in the form of specifying certain relations between $A$ and $B$. Two such conditionalities are those of occurrence in time and space. Accordingly, besides requiring that $\mathrm{A}$ and $\mathrm{B}$ occur before reinforcement is available, one could also require that the occurrence of $A$ precede the occurrence of $B$. Alternatively, one could require that $A$ be on the left and $B$ on the right or that $A$ be on the top and $B$ on the bottom before reinforcement is available. Because such compounds are defined by relations among elements, they will be referred

This research was supported by the Natural Sciences and Engineering Research Council of Canada. Some of these data were presented at the 1978 Canadian Psychological Association Convention, Ottawa, Ontario, Mike Gordon, Brenda Kirkbride, Russell Summers, and Chey Rayner assisted with the experiments. Send reprint requests to Donald M. Wilkie, Department of Psychology, University of British Columbia, Vancouver, Canada V6T 1 W5. to as relational compounds. The two specific varieties of relational compounds described above wil be called temporal and spatial.

Control of responding by relational compounds has received scant experimental study despite its relevance to the long-standing "relational vs. absolute" learning controversy (cf. Köhler, 1955; Spence, 1937). There are only a few published reports on control by temporal compounds. Thomas, Berman, Serednesky, and Lyons (1968) demonstrated discrimination of temporal compounds using a conditioned reinforcement procedure. In their third experiment, 10 food-deprived pigeons received 4,185 pairings of a 1-sec 90-deg white line (A) followed by a 1 -sec $60-$ deg white line (B) followed by food. During subsequent 30 -sec test periods, pecking a white key produced $\mathrm{A}$ alone, $\mathrm{B}$ alone, $\mathrm{A}$ followed by B, B followed by A, or A followed by a novel blank key. Most keypecking occurred during periods in which pecks produced $A$ then $B$; the birds did not respond differentially for the other arrangements.

Kosiba and Logan (1978) arranged four types of trials for eight food-deprived rats (Group 6). On rewarded trials, a light (A) was presented for $.5 \mathrm{sec}$ and followed $.5 \mathrm{sec}$ later by a .5 -sec tone (B); then a barpress produced a food reinforcer. Another type of trial consisted of the reverse order $(B$ then $A)$; barpressing on this trial was not reinforced. On the other two types of trials, $A$ alone and $B$ alone occurred; again, barpressing was not reinforced, Kosiba and Logan presented the data in the form of a discrimination index (percent presses on rewarded trials minus percent presses on nonrewarded trials). The reported terminal index value of 70 indicated some degree of control by the order of $\mathrm{A}$ and $\mathrm{B}$. 
Direct comparisons of responding on $\mathrm{A}$ then $\mathrm{B}$ and $B$ then A trials were not shown.

In their first experiment, Weisman and Dodd (1979) gave eight food-deprived pigeons nine types of trials. Trials began with the presentation of red or green light, designated A and B, or no stimulus, $\mathrm{X}$. After $5 \mathrm{sec}, \mathrm{A}, \mathrm{B}$, or X again occurred for $5 \mathrm{sec}$. Then a white key was presented; pecking this key produced reinforcement when trials began with $\mathrm{A}$ then $B$, but not when trials began with $A$ then $A$, $A$ then $X, B$ then $A, B$ then $B, B$ then $X, X$ then $A, X$ then $B$, or $X$ then $X$. Responding on the white key after $A$ then $B$ exceeded responding after any other compound.

To our knowledge, there are no comparable demonstrations of control by relational spatial compounds. Clarke and Beale (1972), in an attempt to establish such control, gave two pigeons discrimination training between a vertically split pecking key that had red on the left and blue on the right and one that had blue on the left and red on the right. Although both birds differentially responded to the displays, subsequent tests revealed that the birds had discriminated the displays on the basis of the color of only one side of the key. This result demonstrates the necessity of including "two of a kind" displays (e.g., red on both sides and blue on both sides) in studies of spatial compounds.

A major purpose of the present research was to determine if control of pigeons' keypecking by spatial compounds could be established. We chose compounds differing in the left-right location of the elements.

\section{EXPERIMENT 1}

In our first experiment, the left-right location of two colors of light projected onto pecking keys comprised the compound. Two-of-a-kind displays were included. The experimental design contained both between- and within-subjects replications.

\section{Method}

Subjects. Three adult King pigeons were maintained at about $85 \%$ of free-feeding weight by mixed grain obtained during and after daily experimental sessions. The birds had unlimited access to water and grit in their home cages. Birds 77SK-4 and 77SK-5 were experimentally naive; Bird WKA previously had participated in a variety of conditioning experiments.

Apparatus. The test chambers contained three clear plastic pecking keys $(2.5 \mathrm{~cm}$ in diameter) mounted in a row $(8 \mathrm{~cm}$ apart $)$ above the grain feeder. The grain feeder permitted timed access to mixed grain illuminated with a lamp. Industrial Electronics Engineers' Series 10 projectors, mounted behind each key, illuminated the keys with red, green, blue, or yellow light, or with a $2.0 \times .3 \mathrm{~cm}$ white line on a black surround. Pecks with a force of greater than about $.2 \mathrm{~N}$ operated the response-sensing switch on the center key. The outer keys were inoperative. A fan ventilated the chamber and provided masking noise. Programming and data recording were implemented by solid-state circuits and a Data General Nova 3 computer.
Procedure. Bird WKA required no preliminary training. As preliminary training, $77 \mathrm{SK}-4$ and $77 \mathrm{SK}-5$ were trained to eat from the grain feeder, autoshaped to keypeck, and exposed to variableratio reinforcement schedules.

All birds then received 70 to 80 sessions in which each of four types of trials occurred 30 times. The trials were separated by 15-sec intertrial intervals and occurred in a mixed order: In each block of four trials, each of the four types of trials occurred once; the order within each block was varied randomly from block to block. Trials began with the illumination of the inoperative left- and right-hand keys for $5 \mathrm{sec}$. Offset of these stimuli was followed immediately by a 5 -sec illumination of the center key with a white line on a black surround. Pecks to this key were recorded for the first $4.5 \mathrm{sec}$ of the $5-\mathrm{sec}$ presentation. On one type of trial, red (A) appeared on the left and green (B) on the right. Pecking the center key once during the final $.5 \mathrm{sec}$ of the 5-sec presentation produced reinforcement (5-sec access to the grain hopper) on this type of trial (AB). Failure to peck during this .5-sec period resulted in the loss of reinforcement on that trial. Pecking the center key was nonreinforced on the other three types of trials. On one of these, B appeared on the left and $A$ on the right (BA). On another, $A$ appeared on both right and left (AA). On the third type, $B$ appeared on both right and left (BB). Pecks on left and right keys had no programmed consequences. Pecks on the center key when $\mathrm{A}$ and $\mathrm{B}$ were presented and during the intertrial intervals also had no consequences.

The second condition in the experiment was identical to the first except that yellow replaced red as " $\mathrm{A}$ " and blue replaced green as "B."

\section{Results}

The data of primary interest were the number of pecks on the illuminated center key when this key was preceded by the $\mathrm{AB}, \mathrm{BA}, \mathrm{AA}$, and $\mathrm{BB}$ compounds. To facilitate presentation of these data, the numbers of pecks to this key on the four types of trials were summed across all trials in five sessions. These five-session block sums were used to calculate discrimination ratios: Total responses on each of the four types of trials were divided by total responses on the rewarded $A B$ trial. This gave a ratio value of 1.0 for the $A B$ trial. When responding on the nonrewarded trials was less than that on the rewarded trial, the ratios for these trials were less than 1.0.

The discrimination ratios, plotted over blocks of sessions, are shown in Figure 1. Panel 1 shows the original discrimination; Panel 2 shows the results of the replication with different stimuli serving as $A$ and B. Two features of these data are noteworthy. First, the $A B$ compound controlled responding. Discrimination ratios on $\mathrm{BA}, \mathrm{BB}$, and $\mathrm{AA}$ trials were clearly less than 1.0 by the end of the training. Second, while one of the "two of the same" arrangements and the reverse arrangement of the rewarded trial (BA) were readily differentiated from the rewarded $A B$ configuration, differentiation of the other "two of the same" arrangement was slower. This latter effect was especially obvious for WKA and 77SK-5, but was also present, although to a much lesser extent, in 77SK-4's data.

Although the particular "two of the same" ar- 

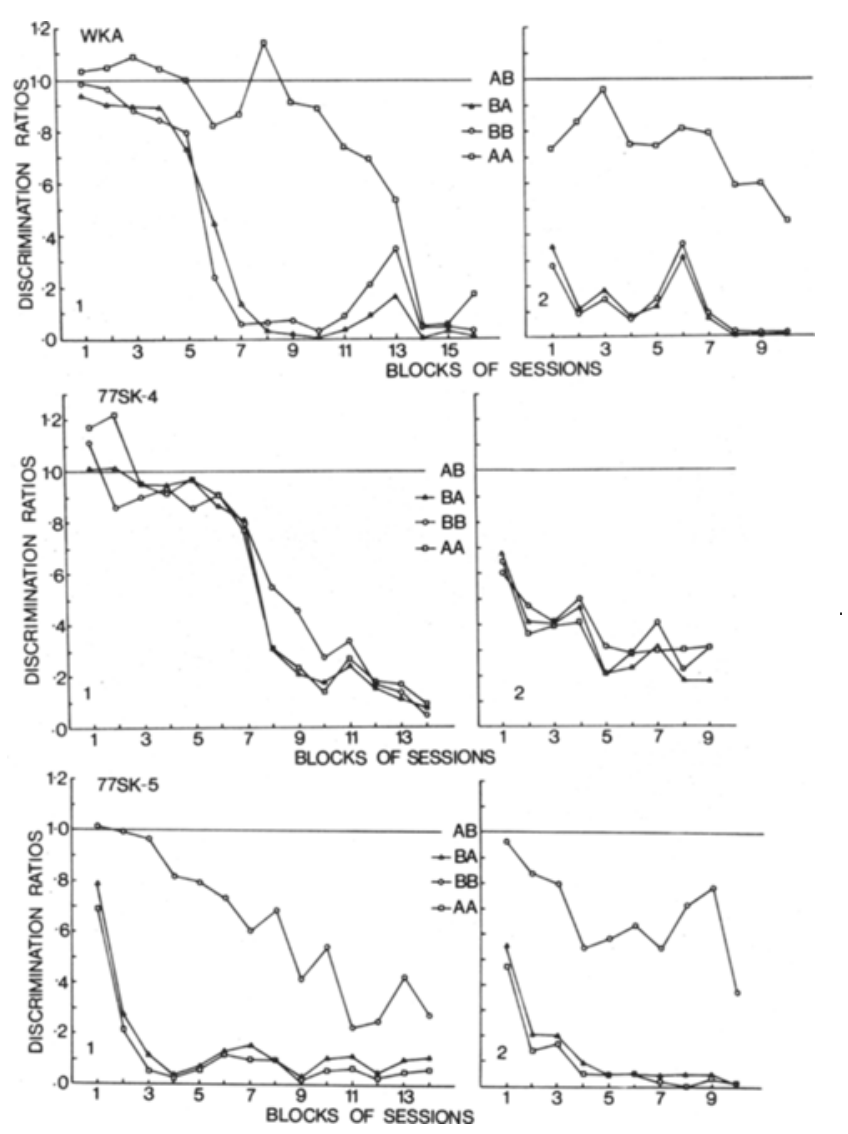

Figure 1. Discrimination ratios in Experiment 1. Ratios were found by dividing responding on all trials $(A B, B A, B B$, and $A A)$ by responding on rewarded $A B$ trials. The different panels correspond to the conditions in which different stimuli served as $A$ and $B$.

rangement that produced most nonrewarded responding early in training differed (AA for WKA; BB for 77SK-5), the same arrangement produced the most nonrewarded responding during the two conditions of the experiment. Consequently, each bird's data displayed a consistent pattern.

\section{Discussion}

The results clearly show that the pigeons differentiated $\mathrm{AB}$ from $\mathrm{BA}, \mathrm{BB}$, and $\mathrm{AA}$. In order to contend that it was the left-right arrangement of the $A$ and $B$ elements that controlled pecking, two issues must be settled. First, is it the relation between elements that controls responding or is responding controlled by other features of the displays? The major source of nonrelational control is control by a particular element in a particular location. Thus, in the absence of "two of a kind" trials, pecking may be controlled by the presence/absence of an element in a particular location (e.g., A on left is associated with reinforcement on one-half of the trials). The inclusion of nonrewarded $\mathrm{BB}$ and $\mathrm{AA}$ trials in the present study precluded this type of con- trol. There was evidence, however, that relational control developed only after a period in which control was nonrelational. The failure of Bird WKA, for example, to differentiate $A A$ from $A B$ in early trials suggests that it was the presence of $A$ on the left key rather than the relation between $A$ and $B$ that controlled responding. Thus, while relational control does develop, as a rule it seems to follow a period of nonrelational control.

The second issue is whether it is the spatial, as opposed to some other, relation between the elements that controls responding. The major alternative is that it is a temporal relation of $\mathbf{A}$ and $\mathbf{B}$ that controls responding. It is possible, because the two side keys were separated by $16 \mathrm{~cm}$, that the pigeons did not see both simultaneously, but rather looked at one and then the other. Then (assuming the pigeons always looked at one side first), the temporal order of $A$ and $B$ rather than their spatial locations could be the controlling relation. While this possibility seems somewhat unlikely, Experiments 2 and 3 were conducted to discount such a possibility.

\section{EXPERIMENT 2}

Four displays of dots projected on a pecking key were used. One dot was a reference point and appeared at the top of the key on all displays. The displays can be described as: dot on right of reference, dot on left of reference, dot on both sides (or two dots), and dot on neither side (or no dots). Dot on right and dot on left are mirror images and have the same relation to each other as $A B$ vs. BA. The two-dot and no-dot displays serve to prevent control by a fraction of the display.

We reasoned that the close spatial proximity of the dots on the key would make serial processing of the elements unlikely.

\section{Method}

Subjects and Apparatus. The same subjects and apparatus as used in Experiment I were used, except that the right-hand key projector was modified to produce four displays. The displays contained from one to three pink dots, each $3 \mathrm{~mm}$ in diameter. On all displays, one dot was centered $9 \mathrm{~mm}$ from the top edge of the key. On one display, this was the only dot present. On another display, an identical dot was located $4 \mathrm{~mm}$ below the top dot, $4 \mathrm{~mm}$ to the right of the center of the key. Another display was similar except that the dot was to the left of center. The fourth display had dots on both sides of the center.

Procedure. Daily sessions consisted of 160 trials. Each of the four types of trials occurred 40 times. The order of trials was mixed: In each block of eight trials, the order was randomized within the constraint that each type of trial had to occur twice. Trials were separated by a 15 -sec intertrial interval.

A trial consisted of a 5.5-sec presentation of the right-hand key. Pecks to this key were recorded during the first $5 \mathrm{sec}$ of presentation. A single peck during the final $.5 \mathrm{sec}$ produced $5 \mathrm{sec}$ access to grain on rewarded trials. A dot on the right was designated as the rewarded trial for WKA and 77SK-4; a dot on the left was designated as the rewarded arrangement for 77SK-5. For all pigeons, pecking on the other three arrangements 
was nonreinforced. Pecking during the intertrial intervals had no consequences.

The second condition was the same as the first except that the spatial arrangement associated with reinforcement availability was reversed from that in the first condition (e.g., a dot on the left was the rewarded display for WKA and 77SK-4).

In the third condition, the relations between the displays and reinforcement availability remained the same as in the second condition. However, each display terminated after $5 \mathrm{sec}$ and was immediately followed by a 5.5 -sec presentation of a red center key. A peck during the final $.5 \mathrm{sec}$ of this presentation produced grain reinforcement when preceded by the rewarded display. Failure to peck during the $.5-\mathrm{sec}$ interval resulted in the loss of reinforcement on that trial. Pecks at the center key were recorded during the first $5 \mathrm{sec}$ of the presentation. Pecks on the right key no longer had any programmed consequences. Pecks on the center key during the intertrial interval had no consequences. During this phase, 80 trials per daily session were given. This condition, like those in Experiment 1, required the pigeon to remember the arrangement of elements after their termination.

\section{Results and Discussion}

The data are presented (Figure 2) in the same fashion as in Experiment 1, with the exception that discrimination ratios were calculated on 3- rather
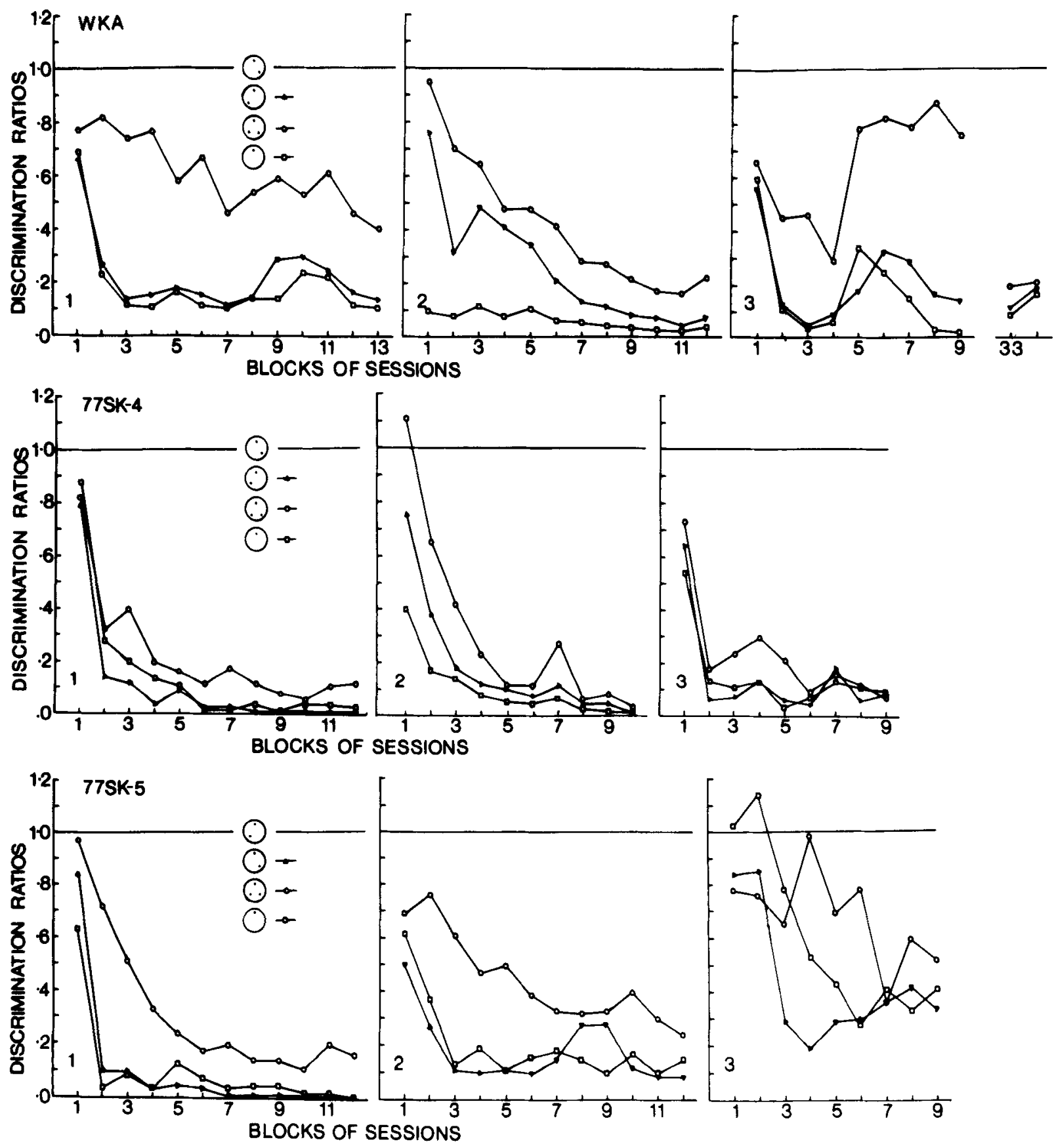

Figure 2. Discrimination ratios in Experiment 2. Ratios were found by dividing responding on all trials (dot on left, dot on right, two dots, no dots) by responding on the rewarded configuration. The different panels correspond to the conditions in which different dot patterns served as the rewarded configuration (Panels 1 and 2 ) and when the pigeons pecked the center key (Panel 3). 
than 5-day sums. Several features of the discrimination ratio data deserve comment. First, it is clear during both initial training and subsequent reversal (Panels 1 and 2, respectively) that the spatial arrangement of stimuli again controlled pecking: Discrimination ratios for the three nonrewarded displays were all less than 1.0 by the end of the training. Because the close spatial proximity of the elements on the dot displays makes serial viewing of the elements unlikely, these results strongly suggest control by the spatial rather than the temporal ordering of the elements. Second, inferior differentiation of one of the nonrewarded displays again was evident early in training, suggesting a degree of nonrelational control. All three pigeons differentiated the two-dot display from the rewarded one-dot display more slowly relative to the other nonrewarded displays. This finding, and the fact that the nonrewarded mirror image of the rewarded one-dot display as well as the no-dot display produced little pecking, suggests that the dot on the right (or left) side of the reference dot was of major importance in controlling pecking early in training.

The two-key arrangement (which required the pigeon to remember the spatial display) shown in the third panel of Figure 2 seemed to result in somewhat poorer control (at least for WKA and 77SK-5) by the spatial configuration of dots than did the one-key arrangements of the preceding two conditions.

It is interesting to note that the same pattern of individual differences that was apparent in Experiment 1 was maintained during all three phases of the present experiment. Control by spatial arrangement was strongest in Subject 77SK-4 throughout. Control was generally weakest in WKA. (Because of the poor control by the two-dot display during the third condition, this phase was extended for 75 sessions for this bird. Data from the last two blocks are appended to Figure 2.)

\section{EXPERIMENT 3}

This experiment was a further attempt to discount the possibility that the subjects may have exposed themselves serially to the elements of the left-right display and thereby learned a temporal rather than a spatial relation discrimination. In the present study, the subjects were forced on half of the trials to process the left-right elements in the order of left element, then right element; on the other half of the trials, they had to process the elements in the reversed order. This was accomplished by presenting the left display slightly before the right display and vice versa.

\footnotetext{
Method

Subjects. Two adult King pigeons were maintained as in the preceding experiments. One bird (RR) was experimentally naive;
}

the other $(\mathrm{JJ})$ had served previously in a matching-to-sample experiment. In preparation for the experiment, Bird RR was trained to eat from the feeder and to peck a key illuminated with red light.

Apparatus. The apparatus was similar to that used in Experiment 1.

Procedure. Each bird first received about 30 sessions of training to peck a key illuminated with red light. Trials were separated by an intertrial interval averaging $20 \mathrm{sec}$. On a random one-third of the 48 trials given each day, the left key was illuminated with red for $5 \mathrm{sec}$. Pecks were recorded during this interval, but these had no consequences. The first peck that occurred after the 5-sec period had elapsed turned off the red light and operated the grain feeder for $5 \mathrm{sec}$. If the bird failed to peck within $2 \mathrm{sec}$ after the end of the initial 5 -sec period, the red light was turned off and no reinforcement was given on that trial. Similar trials were arranged on the center and right keys during the remaining part of the session.

During the experiment proper, subjects received four types of trials in a mixed order during daily sessions comprising 48 trials separated by 30 -sec intertrial intervals. On rewarded AB trials, the left key was illuminated with yellow (A), the right with blue (B), and the center with red. On BA trials, yellow was on the right, blue on the left. On AA and BB trials, both right and left keys were yellow and blue, respectively. On a random one-half of each type of trial, the left key was illuminated $1 \mathrm{sec}$ before the center key and $2 \mathrm{sec}$ before the right key; on the other trials, the right key was illuminated $1 \mathrm{sec}$ before the center and $2 \mathrm{sec}$ before the left key. After all three keys were illuminated, a 5-sec period, during which pecks at the center red key were recorded, began. The first peck that occurred on this key after the 5 -sec period had elapsed produced $5 \mathrm{sec}$ access to grain on the rewarded (AB) trials. If no peck occurred within $2 \mathrm{sec}$ after the end of the 5 -sec period, the trial ended without reinforcement.

Each bird received 37 sessions.

\section{Results and Discussion}

The data are presented in the same fashion as in the preceding experiments, except that discrimination ratios were calculated and plotted for each session rather than blocks of sessions. As can be seen in Figure 3, which shows the discrimination ratios, it is clear that the spatial arrangement of stimuli controlled pecking: Discrimination ratios on $\mathrm{BA}, \mathrm{BB}$, and AA trials were less than 1.0. Again, as well, there was some evidence of nonrelational control during early training sessions. Bird JJ's pecking, in particular, seemed to be controlled during early sessions by a particular color on a particular keyyellow on the left key.

The procedure of presenting the A or B elements of the compound at different times makes the possibility that the pigeons' responding was controlled by the temporal rather than the spatial arrangement of the stimuli very likely.

\section{EXPERIMENT 4}

The generalization test is a commonly used technique to verify that a stimulus controls responding. This procedure was used in this study as a further verification that the spatial relations of $A$ and $B$ controlled responding. Four kinds of generalization 


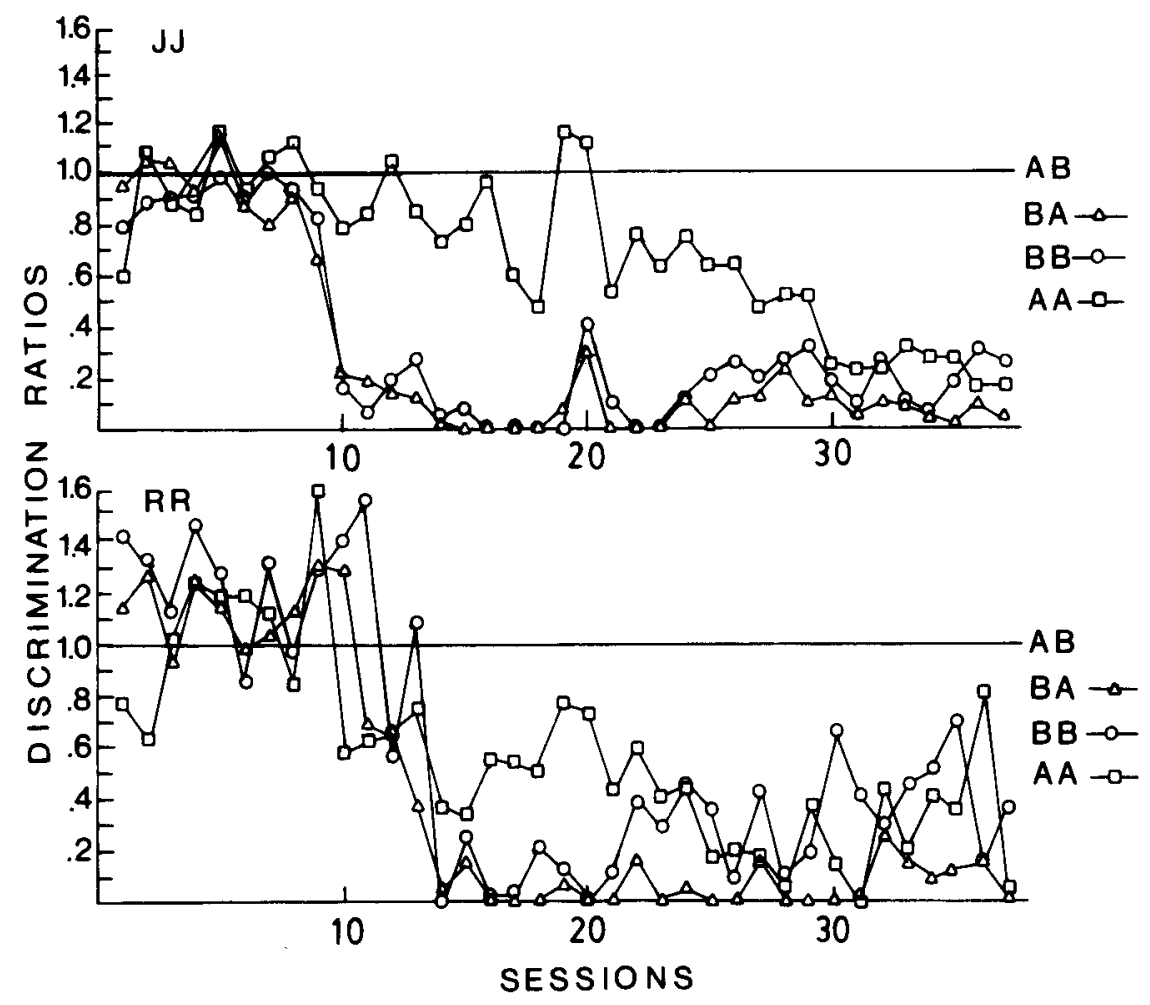

Figure 3. Discrimination ratios in Experiment 3. Details are as in Figure 1.

trials were arranged in which only A or B appeared. In one, A appeared on the left of center; in another, it appeared on the right of center. For the others, $B$ appeared on the left or right of center. If the "A on the left and B on the right" relation controlled responding, one would expect more centerkey responding when $\mathbf{A}$ appeared on the left than when it appeared on the right. Similarly, the converse pattern would be expected with $B$.

\section{Method}

Subjects and Apparatus. The subjects and apparatus were the same as in Experiment 3.

Procedure. This experiment followed Experiment 3 and began with several sessions identical to those arranged in Experiment 3. Then each bird received 11 sessions in which five types of trials occurred. One type of trial was the rewarded $A B$ configuration: These trials occurred with a probability of one-third and were identical to those arranged during Experiment 3. The other four types of trials occurred with a probability of one-sixth. On one of these, yellow (A) appeared on the left, red on the center, and the right was blank (X) (i.e., $\mathrm{AX}$ ). On another, yellow appeared on the right, while the left was blank (XA). On the other two, blue appeared on the left (BX) and right (XB). On these four types of trials, $\mathbf{A}$ or $\mathbf{B}$ either preceded or followed onset of the red center key by $1 \mathrm{sec}$. On each of the four types of trials, the 5 -sec period during which pecks at the red center key were recorded began after both keys were on.

\section{Results and Discussion}

The left-hand panels of Figure 4 show average discrimination ratios for the three baseline sessions; the right-hand panel shows average discrimination ratios for the 11 generalization test sessions in which $\mathrm{AX}, \mathrm{XA}, \mathrm{BX}$, and $\mathrm{XB}$ appeared. Discrimination ratios were calculated as in previous experiments (responding on all types of trials was divided by rewarded $A B$ responding). Both birds responded on test configurations as would be expected if they had learned an "A on the left, B on the right" discrimination: They responded more on $\mathrm{AX}$ than on $\mathrm{XA}$ trials and more on XB than on BX trials.

Since the presence of $\mathrm{A}$ and $\mathrm{B}$ was associated with reinforcement availability, the lower responding to $\mathrm{AX}$ and $\mathrm{XB}$ was also as expected.

Because only single stimuli were used in this study, these results also argue against a temporal ordering account of the AB vs. BA discrimination.

\section{SUMMARY OF RESULTS}

Pigeons clearly can discriminate left-right relational spatial compounds: $\mathrm{AB}$ was differentiated from $\mathrm{BA}$ when the former compound was differentially associated with reinforcement availability. Inclusion of nonrewarded $\mathrm{AA}$ and $\mathrm{BB}$ components prevented the pigeons from discriminating $A B$ from $\mathrm{BA}$ on the basis of a particular element in a particular location (e.g., A on the left or B on the right), and presentation of the $A$ and $B$ elements in close spatial proximity and in a variable temporal order precluded discrimination of $\mathrm{AB}$ from $\mathrm{BA}$ on 


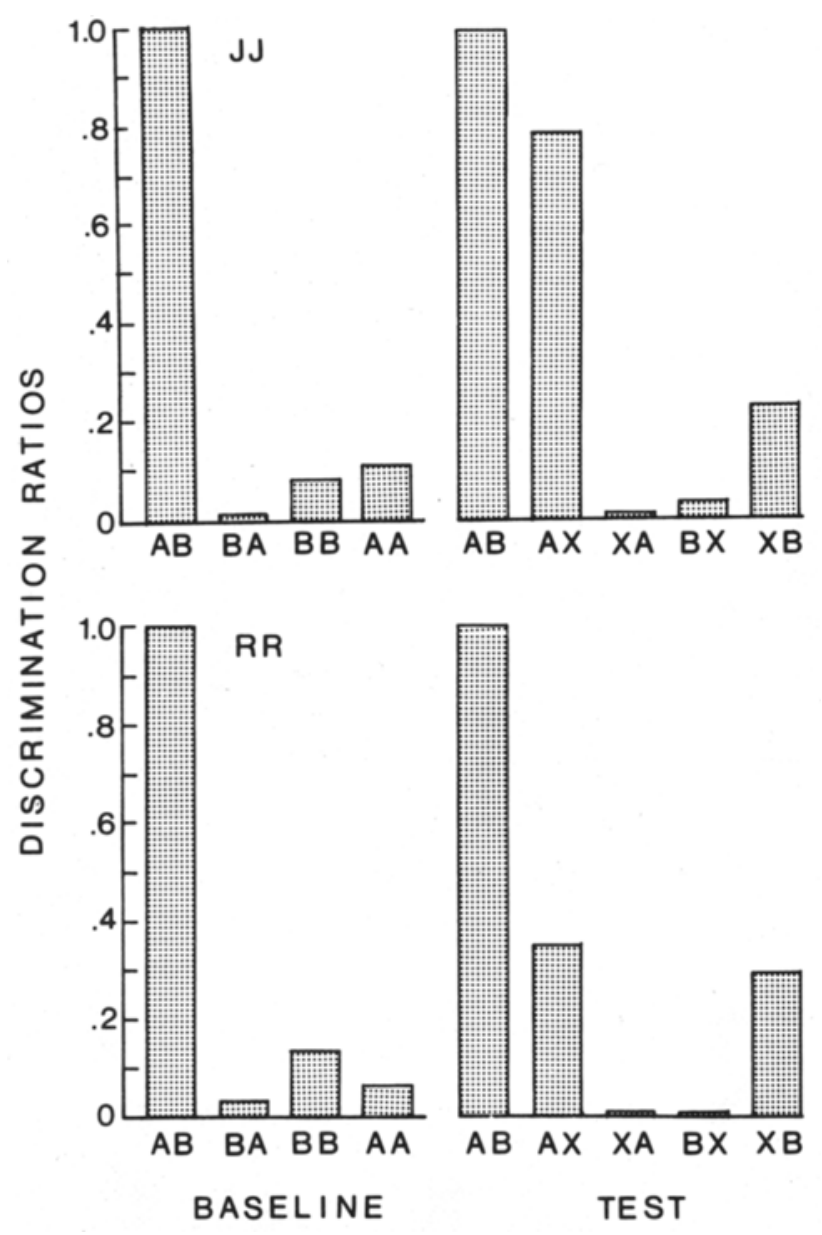

Figure 4. Discrimination ratios in Experiment 4. The left-hand panel shows responding during baseline conditions (AB rewarded; BA, BB, and AA not rewarded). The right-hand panel shows responding when various one-stimulus generalization stimuli $(A X$, $X A, B X, X B)$ were presented in addition to the rewarded $A B$ configuration.

the basis of temporal ordering (cf. Weisman \& Dodd, 1979) of the stimuli.

Control by $A$ on the left and $B$ on the right also was clearly demonstrated during the generalization tests in which A and B were presented singly in the right and left locations: The birds responded more when $A$ appeared on the left or B on the right than when $\mathrm{A}$ appeared on the right or $\mathrm{B}$ on the left.

\section{GENERAL DISCUSSION}

Our results show that pigeons' conditioned keypecking can be controlled by compounds defined by the spatial relationships among the elements. Such results, together with the similar finding that the temporal order of stimuli may control responding (e.g., Weisman \& Dodd, 1979), strongly suggest that relational learning (Köhler, 1955) in animals is possible.
Our results, in addition, show that pigeons are capable of making left-right mirror-image discriminations. Consequently, not all animals have difficulty making such discriminations (cf. Corballis \& Beale, 1976).

While our pigeons clearly learned something about right and left, care must be taken in attempting to infer the nature of this learning. In considering this issue, it will be helpful to keep these three points in mind. First, the distinction between nominal and effective stimuli; second, the fact that the left-right distinction is relative and can be made from several, sometimes redundant, points of reference-consequently, in some of our arrangements, A was to the left of the center key, left of the feeder, left of the midline of the pigeon's body, etc; and third, left-right distinctions can be made in either an absolute ( $A$ is to left of center key) or relative ( $A$ is farther to the left of the chamber door than B) sense.

Was the learning about left and right absolute or relative, and what was the effective point of reference? While definite answers obviously require additional research, it seems possible to rule out at least one possibility from the present data. The results of the single stimulus generalization test (Experiment 4) would seem to argue against a relative interpretation of the learning about the left-right relation of $A$ and $B$. Why, for example, should $A$ in the left location produce more responding than $\mathbf{A}$ in the right location if the learning about the arrangement of $A$ and B was something such as "A is farther left than B"?

\section{REFERENCES}

Clarke, J. C., \& Beale, I. L. Selective stimulus control in discrimination of lateral mirror images by pigeons. Animal Behaviour, 1972, 20, 656-661.

Corballis, M. C., \& Beale, I. L. The psychology of left and right. Hillsdale, N.J: Erlbaum, 1976.

Kehoe, E. J., \& Gormezano, I. Configural and combinational laws in conditioning with compound stimuli. Psychological Bulletin, 1980, 87, 351-378.

KöHLER, W. Simple structural functions in the chimpanzee and in the chicken. In W. D. Ellis (Ed.), A source book of Gestalt psychology. New York: Humanities Press, 1955.

Kosiba, R., \& Logan, F. A. Differential trace conditioning to temporal compounds. Animal Learning \& Behavior, 1978, 6, 205-208.

Spence, K. W. The differential response in animals to stimuli varying within a single dimension. Psychological Review, 1937, 44, 430-444.

Thomas, D. R., Berman, D. L., Serednesky, G. E., \& Lyons, J. Information value and stimulus configuring as factors in conditioned reinforcement. Journal of Experimental Psychology, 1968, 76, 181-189.

Weisman, R. G., \& Dodn, P. W. D. The study of association: Methodology and basic phenomena. In A. Dickenson \& R. A. Boakes (Eds.), Mechanisms of learning and motivation: $A$ memorial volume for Jerzy Konorski. Hillsdale, N.J: Erlbaum, 1979.

(Received for publication July 18, 1979; revision accepted July 21,1980 .) 